\title{
Heterostructured Langmuir-Blodgett Films of Ruthenium Bipyridine with 1,3,4-Naphthooxadiazole-Derived Amphiphile Complex as a Charge Storage Electrode
}

\author{
Herbert Winnischofer, ${ }^{\circledR} * a$ Elizangela C. Cesca, ${ }^{a}$ Alejandro E. P. Mendoza, ${ }^{\oplus a}$ \\ Iolanda P. Araújo, ${ }^{\circledR a}$ Eduard Westphal, ${ }^{b, c}$ Daniela Z. Mezalira, ${ }^{c}$ Débora T. Balogh ${ }^{d}$ and \\ Osvaldo N. Oliveira Jr. ${ }^{d}$ \\ ${ }^{a}$ Departamento de Química, Universidade Federal do Paraná, \\ CP 19032, 81531-980 Curitiba-PR, Brazil \\ ${ }^{b}$ Departamento Acadêmico de Química e Biologia, Universidade Tecnológica Federal do Paraná, \\ 81280-340 Curitiba-PR, Brazil \\ ${ }^{c}$ Departamento de Química, Universidade Federal de Santa Catarina, \\ 88040-900 Florianópolis-SC, Brazil \\ ${ }^{d}$ Instituto de Física de São Carlos, Universidade de São Paulo, \\ CP 369, 13560-970 São Carlos-SP, Brazil
}

\begin{abstract}
The molecular control in Langmuir-Blodgett (LB) films may be exploited in charge storage electrodes provided a suitable choice of molecular architecture and components is made. In this paper, we employed a naphtyl-1,3,4-oxadiazole amphiphile (NFT1) and its complex $\left[\mathrm{Ru}(\mathrm{bpy})_{2} \mathrm{NFT} 1 \mathrm{PF}_{6}\right.$ (RuNFT1) (bpy $=2,2^{\prime}$-bipyridine) in heterostructured LB films in a proof-of-principle production of charge storage. The optimized architecture contained a one-layer RuNFT1 deposited on a 9-layer NFT1 LB film, where the efficient packing of NFT1 inferred from spectroscopic measurements and Brewster angle microscopy (BAM) images was considered as relevant for ion diffusion. This packing was achieved owing to the $\pi$-stacking warranted by the planarity of the NFT1 naphtyl 1,3,4-oxadiazole ring, as confirmed with density functional theory (DFT) calculations. The top layer of the redox-active RuNFT1 provided an additional contribution with its Faradaic charge storage to the double layer capacitance of NFT1. Taken together, these results demonstrate that synergy may be achieved in combining distinct compounds in LB films toward efficient charge storage.
\end{abstract}

Keywords: charge storage, Langmuir-Blodgett, ruthenium, oxadiazole

\section{Introduction}

The control of materials properties inherent in nanotechnology has been exploited in many areas, including in applications of molecular nanotechnology $\mathrm{y}^{1,2}$ in which ordered nanomaterials and nanodevices are produced with bottom-up approaches. Also relevant in this context is the self-assembly of specific molecular geometries via supramolecular chemistry ${ }^{3}$ involving weak forces such as intermolecular hydrogen bonds and hydrophobic interactions. These self-assembled structures may incorporate transition metal ions that bind within

*e-mail: hwin@ufpr.br; hwin.ufpr@gmail.com

Dedicated to Prof Henrique Eisi Toma on the occasion of his $70^{\text {th }}$ birthday. several coordination sphere geometries and assume distinct oxidation numbers. ${ }^{3}$ This latter property is important for electrochemical devices to supply the energy-storage demand, particularly for electronic equipment and integrated microsystems which require energy storage with thin geometries, planar arrays and flexible structures. ${ }^{4,5}$ These devices should ideally have high capacity, stability during their functioning and fast charge/discharge, which can be achieved with portable supercapacitors. ${ }^{5-7}$

Supercapacitors are based on electrical double layers, and offer high power but with low energy density, unlike batteries. ${ }^{7-9}$ An alternative to increase the energy of supercapacitors is to use materials with storage mechanisms beyond the electrical double layer but keeping the capacitive behavior and high-rate capabilities. Pseudo- 
capacitors are interesting in this regard, as they possess redox reactions and intercalation processes typical of batteries, in addition to a capacitive behavior. Materials employed in super-capacitors include conducting polymers, ${ }^{10,11}$ transition metal oxides ${ }^{8,12}$ and composites, ${ }^{13-15}$ which exhibit high capacitance though they have inefficient mass transport or low stability. ${ }^{8,11}$ A possibility so far scarcely explored is to use metal coordination compounds whose properties can be tuned via the choice of metals and ligands. Ruthenium, in particular, is a multivalent metal in a diversity of coordination compounds and applied in many areas. ${ }^{16,17} \mathrm{Ru}$-based compounds present reversible electrochemical reactions that can be harnessed in energy storage applications. With regard to shortening ion pathway distances, use can be made of electrodes obtained in the form of Langmuir-Blodgett (LB) films. ${ }^{18}$ Indeed, the layer-by-layer nature of LB films may favor formation of channels for ion transport and, consequently, the charge transport within the film. ${ }^{18}$

Thin films of molecular materials based on ruthenium complexes have been the focus of our studies for more than a decade. Polyruthenated porphyrins ${ }^{19-22}$ were initially chosen because of the ability of the planar polypirrol ring to form columnar stacking structures by hydrophobic $\pi-\pi$ interactions. With layer-by-layer films ${ }^{23}$ we observed the effect of film deposition on the molecular organization and electrochemical response of porphyrins. ${ }^{24}$ Our group has also employed the LB technology, which is the ultimate method for precise control of molecular monolayer transfer onto a solid substrate, with which we noted that the geometry of the amphiphiles determines molecular packing and electrochemical response. ${ }^{25,26}$ Significantly for the present study, we observed that heterostructured films of highly ordered structures, and a single monolayer of electroactive ruthenium amphiphile, exhibit an improved electrochemical response due to the efficient charge hopping through the aryl groups of the organic amphiphiles and ruthenium centers. ${ }^{26}$

Herein, we aimed at investigating the role of molecular ordering of LB films on their charge storage capacity. We designed and synthesized a naphtyl 1,3,4-oxadiazole derived amphiphile (NFT1, Scheme 1) to improve the ability to form dense Langmuir monolayers and obtain higher efficiency on double layer capacitance in LB films. The choice of 1,3,4-oxadiazole heterocycle was made since its aryl derivatives exhibits intense luminescence and high emission quantum yields, ${ }^{27}$ being also employed in liquid crystals $^{28,29}$ with suitable properties for OLED devices. ${ }^{30}$ For example, Chen et al. ${ }^{31}$ built an electroluminescent cell based on an 1,3,4-oxadiazole copolymer, since the aryl heterocycle behaves as an efficient electron carrier due to the strong $\pi$-acceptor character. The ruthenium complex (RuNFT1, Scheme 1) was synthesized and the effect of the NFT1 ligand on the metal coordination sphere and its charge storage capacity in the LB films were characterized.
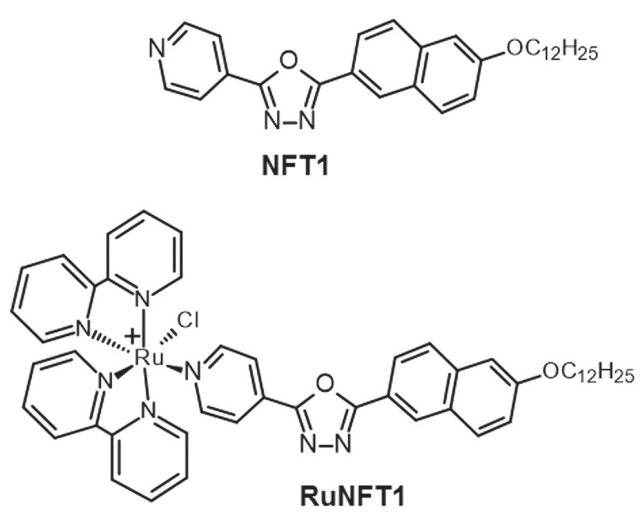

Scheme 1. NFT1: 2-(6-dodecyloxy-2-naphthyl)-5-(4-pyridyl)1,3,4-oxadiazole and the complex RuNFT1: $\left[\mathrm{Ru}(\mathrm{bpy})_{2} \mathrm{NFT}_{\mathrm{Cl}}\right]^{+} \mathrm{PF}_{6}{ }^{-}$is the counter ion.

\section{Experimental}

\section{Materials}

All reagents and solvents were of analytical grade. The compound 4-(tetrazole-5-yl)-pyridine (5) was synthesized according to a procedure in the literature. ${ }^{32}$ All solutions for the cyclic voltammetry experiments were prepared with dichloromethane previously dried with $\mathrm{CaCl}_{2}$ for 30 min and then distilled from $\mathrm{CaH}_{2} . \mathrm{RuCl}_{3}$ with $45 \%$ purity (Sigma-Aldrich, Saint Louis, Missouri, USA) was used as received.

\section{Structural characterization of molecules}

The molecular structure and purity of synthesized compounds were confirmed with a few techniques. Elemental analysis was performed in a $2400 \mathrm{CHN}$ Series II Elemental Analyzer from PerkinElmer. ${ }^{1} \mathrm{H}$ and ${ }^{13} \mathrm{C}$ nuclear magnetic resonance (NMR) spectra were recorded at $303 \mathrm{~K}$ on a Bruker spectrometer operating at 200 and 50.6 MHz, employing deuterated chloroform $\left(\mathrm{CDCl}_{3}\right)$ as solvent and $0.1 \%$ tetramethylsilane (TMS) as internal standard. High resolution mass spectra (HRMS) were acquired on a Bruker micrOTOF-Q II mass spectrometer by using an APPI ionization source.

\section{Thermal measurements}

Melting points and liquid crystalline textures were determined with an Olympus BX50 microscope equipped 
with a Mettler Toledo FP-82 Hot Stage and an Olympus DP73 digital camera. The DSCQ2000 calorimeter with a RCS90 cooling system was used for differential scanning calorimetry (DSC) measurements, with heating/ cooling rates of $10{ }^{\circ} \mathrm{C} \mathrm{min}^{-1}$ under nitrogen atmosphere (50 $\mathrm{mL} \mathrm{min}^{-1}$ flow).

\section{LB films, preparation of monolayers and deposition}

Deposition of LB films and surface pressure-molecular area ( $\Pi$-A) isotherms were conducted at ca. $20^{\circ} \mathrm{C}$ in a Nima Technology 311D trough system. The П-A curves were obtained at several barrier speeds. $0.77 \mathrm{mg} \mathrm{mL}^{-1}$ (NFT1) and $0.60 \mathrm{mg} \mathrm{mL}^{-1}$ (RuNFT1) dichloromethane solution of the investigated compound was spread onto an ultrapure water subphase with the aid of a microsyringe. Y-type ${ }^{33} \mathrm{LB}$ films were prepared on fluorine doped tin oxide (FTO), quartz or gold substrates, by successive depositions of monolayers of the amphiphilic species at $29 \mathrm{mN} \mathrm{m}^{-1}$ (NFT1) and $21 \mathrm{mN} \mathrm{m}^{-1}$ (RuNFT1) constant surface pressure, at $100 \mathrm{~cm}^{2} \mathrm{~min}^{-1}$ and $100 \mathrm{~mm}^{2} \mathrm{~min}^{-1}$ barrier and dipping speeds, respectively. For the electrochemical tests, 9-layer LB NFT1 and RuNFT1 films were deposited on FTO. The RuNFT1-NFT1 heterostructured film was obtained with 9 monolayers of NFT1, with the first monolayer deposited while the substrate immerges into the subphase, and a single monolayer of RuNFT1 also deposited in the immerging direction, over the top.

\section{UV-Vis spectroscopy}

An Agilent HP 8453 spectrophotometer was used to obtain the UV-Vis spectra from chloroform solutions and LB films deposited on quartz.

\section{Infrared spectroscopy}

A Bruker Vertex 70 spectrophotometer was used to record infrared (IR) spectra of the compounds embedded in $\mathrm{KBr}$ pellets in transmittance mode (4000 to $400 \mathrm{~cm}^{-1}$ range and $4 \mathrm{~cm}^{-1}$ resolution) while an A518/Q specular reflectance unit with a grazing angle accessory at $80^{\circ}(4000$ to $600 \mathrm{~cm}^{-1}$ range and $8 \mathrm{~cm}^{-1}$ resolution) was employed for IRRAS (infrared reflection absorption spectroscopy) of 20-monolayer LB films deposited on gold substrates. Polarized spectra were collected at 0 and $90^{\circ}$ by using an F-350 mid-infrared (MIR) polarizer, KRS-5 (TIBr/TII) optical crystals, and an A-110 rotatable holder. Langmuir films on ultrapure water were analyzed using PM-IRRAS (polarization-modulated infrared reflection absorption spectroscopy) in a PMI 550 spectrophotometer from
KSV Instruments with a $\mathrm{HgCdTe}$ detector (MCT) with incident light at $80^{\circ}$ relative to the normal, with radiation modulated between parallel ( $p$-polarized) and perpendicular $\left(s\right.$-polarized) in the 4000 to $800 \mathrm{~cm}^{-1}$ range and $8 \mathrm{~cm}^{-1}$ resolution, coupled to a KSV Minitrough with two barriers. Compression speed: $10 \mathrm{~mm} \mathrm{~min}^{-1}$, temperature: $21^{\circ} \mathrm{C}$.

\section{Raman spectroscopy}

A WiTec alpha 300R spectrophotometer was used with a CCD detector (charge-coupled device), using 532 and $633 \mathrm{~nm}$ lasers with power of $31 \mu \mathrm{W}$ as excitation source.

\section{Brewster angle microscopy (BAM)}

An Accurion Nanofilm EP4 equipment was coupled to a Langmuir trough from KSV model Minitrough with a laser source $(\lambda=658 \mathrm{~nm})$ and ultra-objective lens. $60 \mu \mathrm{L}$ NFT1 (0.41 $\left.\mathrm{mg} \mathrm{mL}^{-1}\right)$ and $60 \mu \mathrm{L}$ RuNFT1 (0.60 $\left.\mathrm{mg} \mathrm{mL}^{-1}\right)$ dichloromethane solutions were spread over the aqueous subphase. Compression speed: $10 \mathrm{~mm} \mathrm{~min}^{-1}$, temperature: $21{ }^{\circ} \mathrm{C}$.

\section{Electrochemistry}

Cyclic voltammetry measurements were performed on an Ivium Compactstat potentiostat/galvanostat in a threeelectrode cell system consisting of $\mathrm{Ag} / \mathrm{Ag}^{+}\left(0.01 \mathrm{~mol} \mathrm{~L}^{-1}\right.$ in acetonitrile) reference electrode, $3 \mathrm{~mm}$ platinum disc working electrode, and platinum wire counter electrode. Dichloromethane solutions of the compounds at $1 \mathrm{mmol} \mathrm{L}^{-1}$ were analyzed, using $0.1 \mathrm{~mol} \mathrm{~L}^{-1} \mathrm{TBAClO}_{4}$ as electrolyte solution. Film electrochemistry was investigated using LB films deposited on FTO as working electrodes, Ag/ $\mathrm{AgCl}\left(\mathrm{NaCl} 3 \mathrm{~mol} \mathrm{~L}^{-1}\right)$ as reference electrode, a platinum wire as counter-electrode and aqueous $\mathrm{KCl} 0.5 \mathrm{~mol} \mathrm{~L}^{-1}$ as electrolyte solution. Charge and discharge measurements (chronopotentiometry) were performed using cut-off potentials of -0.08 and $0.97 \mathrm{~V}(v s \mathrm{Ag} / \mathrm{AgCl})$ and 4 cycles for each charge-discharge current. Electrochemical impedance spectroscopy (EIS) measurements were carried out within a frequency range from 0.1 to $10^{5} \mathrm{~Hz}$, fixed potentials of 0.85 and $0 \mathrm{~V}(v s \mathrm{Ag} / \mathrm{AgCl})$ and a potential amplitude of $0.01 \mathrm{~V}$. The results are reported with respect to standard hydrogen electrode (SHE).

\section{Theorical calculations}

Density functional theory (DFT) calculations were performed with Orca version 4, ${ }^{34,35}$ using the Ahlrichs split valence basis $\operatorname{set}^{36}$ (def2-SVP), effective core potentials 
for $\mathrm{Ru}$ atoms, the auxiliary basis set $\operatorname{def} 2 / \mathrm{j}$ for RI-J approximation for Coulomb integrals, ${ }^{37}$ and Grimme's DFT-D3 dispersion correction. ${ }^{38,39}$ The BP86 $6^{40,41}$ functional was used for geometry optimizations, whereas single point energy calculation was carried out on the optimized structures using the PBE $0^{42}$ hybrid functional and larger integration grid for higher accuracy in derived properties.

\section{Synthesis}

Ligand 2-(6-dodecyloxy-2-naphthyl)-5-(4-pyridyl)1,3,4-oxadiazole (NFT1)

In the first step of the synthetic procedure (Scheme 2), 1.5 $\mathrm{g}(7.98 \mathrm{mmol})$ of 6-hydroxy-2-naphthoic acid (1) in $30 \mathrm{~mL}$ ethyl alcohol (PA) was mixed with $0.2 \mathrm{~mL}$ concentrated sulfuric acid and kept under reflux for $18 \mathrm{~h}$. The solvent was removed by vacuum roto-evaporation, and the remaining solid was dissolved in $30 \mathrm{~mL}$ ethyl acetate and washed with distilled water $(3 \times$ of $10 \mathrm{~mL})$. Then, the solution was dried with anhydrous sodium sulfate to remove water and the solvent was evaporated, resulting in compound $\mathbf{2}$, which was used without further purification. Compound 2 was mixed with $1.49 \mathrm{~g}$ (10.6 mmol) $\mathrm{K}_{2} \mathrm{CO}_{3}$ and $2.02 \mathrm{~g}$ (7.98 mmol) $\mathrm{C}_{12} \mathrm{H}_{25} \mathrm{Br}$ in $50 \mathrm{~mL}$ butanone and refluxed under stirring for $18 \mathrm{~h}$. The mixture was then filtered to remove insoluble residues and the solvent was evaporated, providing the crude compound $\mathbf{3}$, which was used in the following step without purification. Compound 4 was obtained by ester hydrolysis of $\mathbf{3}$ using $0.641 \mathrm{~g}$ (16 mmol) of $\mathrm{KOH}$ dissolved in $20 \mathrm{~mL}$ distilled water and $40 \mathrm{~mL}$ ethanol. The mixture was kept under reflux and stirred for $3 \mathrm{~h}$ at $60{ }^{\circ} \mathrm{C}$. This mixture was partially evaporated and $80 \mathrm{~mL}$ distilled water and hydrochloric acid were added to adjust the $\mathrm{pH}$ to ca. 2. The precipitated solid was isolated by filtration and purified by recrystallization from hot ethanol/ $\mathrm{H}_{2} \mathrm{O}$ solution, forming white crystals. The second step started by mixing $0.5 \mathrm{~g}$ ( $1.4 \mathrm{mmol})$ of compound $\mathbf{4}, 0.25 \mathrm{~g}(1.4 \mathrm{mmol})$ of compound $\mathbf{5}$ (4-(tetrazole-5-yl)-pyridine) and $0.0085 \mathrm{~g}(0.07 \mathrm{mmol})$ of $N, N$-dimethylaminopyridine (DMAP) in $30 \mathrm{~mL}$ toluene. $0.35 \mathrm{~g}(1.7 \mathrm{mmol})$ dicyclohexylcarbodiimide (DCC) was added to the mixture and kept at $110{ }^{\circ} \mathrm{C}$ for $48 \mathrm{~h}$. Then, distilled water was added and the solid precipitated was removed by filtration and discarded. The solvent was removed from the filtrate resulting in the crude product. The final compound (NFT1) was purified by chromatography in a silica gel column using dichloromethane/ethyl acetate mixture (80:20) as eluent, followed by a recrystallization from hot ethanol. Yield: 46\%; mp (liquid crystal) $\mathrm{Cr} 107^{\circ} \mathrm{C} \mathrm{SmA} 118^{\circ} \mathrm{C}$ Iso.

\section{Synthesis of ruthenium precursor}

The precursor cis-[ $\left.\mathrm{Ru}(\mathrm{bpy}){ }_{2} \mathrm{Cl}_{2}\right] \cdot 2 \mathrm{H}_{2} \mathrm{O}$ (bpy $=2,2$ '-bipyridine) was synthesized following the procedure described in literature ${ }^{43}$ by refluxing $\mathrm{RuCl}_{3} \cdot 3 \mathrm{H}_{2} \mathrm{O}$ with two equivalents of bpy and excess of $\mathrm{LiCl}$ in $N, N$-dimethylformamide (DMF).

\section{$\left[\mathrm{Ru}(\mathrm{bpy})_{2} \mathrm{Cl}(\mathrm{NFT} 1)\right] \mathrm{PF}_{6}$ (RuNFT1)}

In a $100 \mathrm{~mL}$ two-neck round-bottom flask, $0.050 \mathrm{~g}$ (0.103 mmol) $\left[\mathrm{Ru}(\mathrm{bpy})_{2} \mathrm{Cl}_{2}\right] \cdot 2 \mathrm{H}_{2} \mathrm{O}$ was mixed with $0.018 \mathrm{~g}$ $(0.103 \mathrm{mmol}) \mathrm{AgNO}_{3}$ in $20 \mathrm{~mL}$ of ethanol solution, and
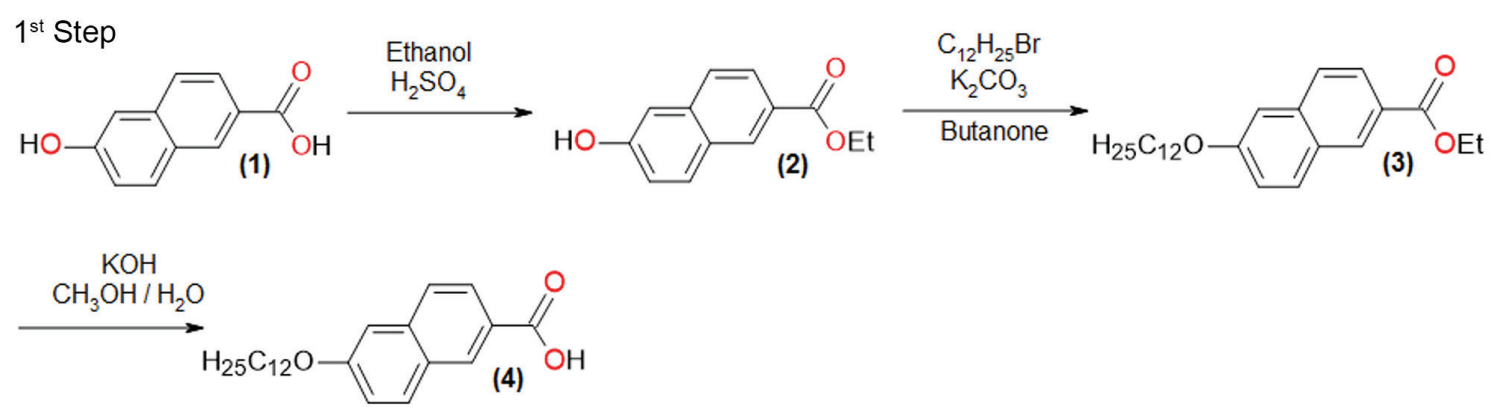

$2^{\text {nd }}$ Step

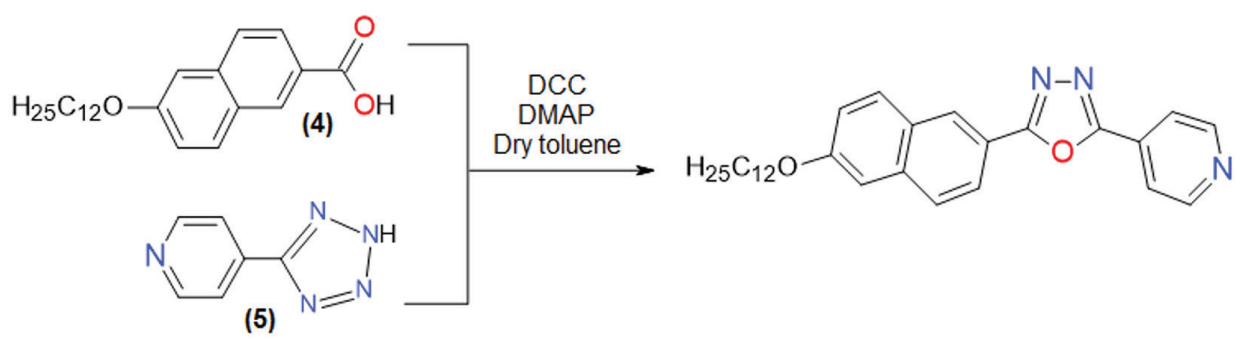

Scheme 2. Synthetic route used to obtain the ligand NFT1. 
kept under reflux for 30 min under argon atmosphere. After cooling to room temperature, the mixture was filtered to remove silver chloride. The filtrate was transferred to a flask containing $0.047 \mathrm{~g}(0.103 \mathrm{mmol}) \mathrm{NFT} 1$ and the mixture heated and kept under reflux for $16 \mathrm{~h}$. After the system was cooled to room temperature, $\mathrm{NH}_{4} \mathrm{PF}_{6}$ (in excess) was added starting precipitation. The solution was kept in the freezer overnight to further increase the yield. The solid was filtered and washed with ethanol and dried in a desiccator with calcium chloride under vacuum. Yield: $57 \%$.

\section{Results and Discussion}

\section{Characterizations}

The electrospray ionization mass spectrometry (ESI-MS), ${ }^{1} \mathrm{H}$ NMR, Fourier-transform infrared spectroscopy (FTIR) and elemental analysis data confirmed the molecular structure and purity of NFT1 and RuNFT1 in Scheme 1. These results are shown in Figures S1-S5 in the Supplementary Information (SI) section. The electronic spectrum of NFT1 in dichloromethane solution in Figure S6a shows $\pi-\pi^{*}$ absorption bands at $271 \mathrm{~nm}$ (molar absorptivity, $\varepsilon=3.97 \times 10^{4} \mathrm{~mol}^{-1} \mathrm{~L} \mathrm{~cm}^{-1}$ ) and $333 \mathrm{~nm}\left(\varepsilon=3.77 \times 10^{4} \mathrm{~mol}^{-1} \mathrm{~L} \mathrm{~cm}^{-1}\right)$. The complex RuNFT1 exhibited $\pi-\pi^{*}$ absorption bands at $295 \mathrm{~nm}\left(\varepsilon=7.11 \times 10^{4} \mathrm{~mol}^{-1} \mathrm{~L} \mathrm{~cm}^{-1}\right)$ and $344 \mathrm{~nm}$ $\left(\varepsilon=1.84 \times 10^{4} \mathrm{~mol}^{-1} \mathrm{~L} \mathrm{~cm}^{-1}\right)$ assigned to NFT1 intraligand $\pi-\pi^{*}$ transitions and at $406 \mathrm{~nm}\left(\varepsilon=2.19 \times 10^{4} \mathrm{~mol}^{-1} \mathrm{~L} \mathrm{~cm}^{-1}\right)$, $463 \mathrm{~nm}\left(\varepsilon=1.62 \times 10^{4} \mathrm{~mol}^{-1} \mathrm{~L} \mathrm{~cm}^{-1}\right)$ and $499 \mathrm{~nm}$ $\left(\varepsilon=1.48 \times 10^{4} \mathrm{~mol}^{-1} \mathrm{~L} \mathrm{~cm}^{-1}\right)$ assigned to metal-to-ligand charge-transfer (MLCT) transitions. NFT1 did not exhibit redox processes in the analyzed potential window of the dichloromethane solution, but the complex RuNFT1 had a single reversible redox pair with $\mathrm{E}_{1 / 2}=1.07 \mathrm{~V}$ ( $\left.v s \mathrm{SHE}\right)$, which was assigned to the $\mathrm{Ru}^{\mathrm{III} / \mathrm{II}}$ process (Figure $\mathrm{S} 6 \mathrm{~b}$ ). The $\mathrm{I}_{\mathrm{P}}$ versus $\mathrm{v}^{1 / 2}$ plot in Figure $\mathrm{S} 6 \mathrm{c}$ has a slope near $45^{\circ}$ characteristic of a reversible, diffusion limited process. The potential is independent of the scanning speed and the peak current ratio was $\mathrm{I}_{\mathrm{pc}} / \mathrm{I}_{\mathrm{pa}}$ ca. 1 . Using the Lever ${ }^{44}$ electrochemical parameterization model we calculated the NFT1 electrochemical parameter $\left(E_{L}\right)$ from the experimental $\mathrm{E}_{1 / 2}$ value and the tabulated parameters for bipyridine $(0.259 \mathrm{~V})$ and chloride $(-0.24 \mathrm{~V})$. The contribution of NFT1 ligand to the displacement of the redox potential of $\mathrm{Ru}^{\mathrm{III} / \mathrm{II}}$ has an additive value of $\mathrm{E}_{\mathrm{L}}=+0.274 \mathrm{~V}$. Upon comparing with a similar oxadiazole derivative ${ }^{45}$ (2-(4-dodecyloxyphenyl)-5-(4-pyridyl)-1,3,4-oxadiazole) we could infer that the naphthyl group decreases the $\pi$-acceptor character on the 4-oxadiazolepyridine binding site, in comparison to the benzene group. ${ }^{45}$

\section{DFT calculations}

Frontier molecular orbitals of the complexes $\mathrm{Ru}^{\mathrm{II} / \mathrm{III}} \mathrm{NFT} 1$ and NFT1 ligand in "gas phase" were calculated. The contribution of the fragments to molecular orbitals in the complexes is reported in Table S1 and illustrated in Figures S7-S8 (SI section). The frontier orbitals in complex Ru ${ }^{\mathrm{II}} \mathrm{NFT} 1$ are delocalized over the whole molecule. Occupied frontier orbitals involve mainly the naphthyl group (HOMO and HOMO-3) or lies on ruthenium and chlorine atoms (HOMO-1 and HOMO-2). The unoccupied frontier orbitals have contributions from the pyridine fragment of NFT1 (LUMO+2) or from the bipyridine (bpy) ligands (LUMO, LUMO+1, LUMO+3). From these data the intraligand $\pi-\pi *$ transitions at NFT1 fragment would be expected to occur at lower wavelengths (involving HOMO-3 to LUMO+2 transition) than the metal-to-ligand charge transfer bands: Ru(HOMO1) $\rightarrow$ bpy(LUMO, LUMO+1); Ru(HOMO-1) $\rightarrow$ NFT1 (LUMO+2). LUMO and LUMO+1 are close in energy and the electronic transitions involving these orbitals should appear as superimposed bands. Besides, the NFT1 frontier orbitals have a main contribution from the naphthyl fragment. Some of these orbitals cover the whole ligand fragment and others are more localized on pyridine and oxadiazole fragments (LUMO and HOMO-3). Therefore, the naphthyl unit is assumed to be the main group involved in the electronic transitions.

The energy of the electronic transitions can be estimated using the orbital energies of the minimum energy state. The transitions energy values calculated within this approximation are not exact but provide a qualitative picture of electronic transitions. The results are shown in Table S2 (SI section). Ru(d) $\rightarrow$ bpy $(\pi)$ MLCT and $\pi-\pi^{*}$ intraligand NFT1 transitions in the complex $\mathrm{Ru}^{\mathrm{II}} \mathrm{NFT} 1$ were estimated as $3.04 \mathrm{eV}(407 \mathrm{~nm})$ and $4.27 \mathrm{eV}$ (290 nm). The experimental MLCT value in dichloromethane solution is $406 \mathrm{~nm}$. The bpy intraligand $\pi-\pi^{*}$ band appears at $295 \mathrm{~nm}$, but the NFT1 intraligand $\pi-\pi^{*}$ transition may be superimposed. Interestingly, the frontier orbitals, especially the HOMO, are drastically modified when $\mathrm{Ru}^{\mathrm{II} N F T 1}$ is oxidized to Ru${ }^{\mathrm{III} N F T 1}$. The highest occupied orbital corresponds to a singly occupied molecular orbital ( $\beta$-SOMO) delocalized over the complex $\mathrm{Ru}^{\mathrm{III}} \mathrm{NFT} 1$ and involves mainly the naphthyl fragment and the ruthenium ion. The other occupied orbitals $\alpha-\beta$ HOMO- 1 , $\alpha-\beta$ HOMO-2 and HOMO-3 correspond to doubly occupied orbitals and are localized in the dodecyloxy fragment of NFT1 ligand, whilst $\beta$-LUMO is delocalized over the whole molecule with most contribution of the naphthyl fragment and ruthenium ion, just as the $\beta$-SOMO 
orbital. The $\alpha-\beta$ LUMO+1 and LUMO+2 have main contributions from bipyridines. The $\alpha-\beta$ LUMO +3 orbital has main contribution from the NFT1 ligand. The $\beta$-SOMO and $\beta$-LUMO differ by only $0.57 \mathrm{eV}$ and the energy difference between other occupied orbitals ( $\alpha-\beta$ HOMO- 1 , $\alpha-\beta$ HOMO-2 and HOMO-3) and $\beta$-LUMO is lower than $1 \mathrm{eV}$. Therefore, we could expect bathochromic shifts in the absorption bands with the oxidation of the complex $\mathrm{Ru}^{\mathrm{II}} \mathrm{NFT} 1$ to $\mathrm{Ru}^{\mathrm{III}} \mathrm{NFT} 1$. The MLCT $\mathrm{Ru}(\mathrm{d}) \rightarrow \operatorname{bpy}(\pi)$ and NFT1 intraligand $\pi-\pi^{*}$ transitions are estimated at $2.33 \mathrm{eV}$ $(533 \mathrm{~nm})$ and $3.15 \mathrm{eV}(393 \mathrm{~nm})$, respectively, which corresponds to ca. $100 \mathrm{~nm}$ shift to higher wavelengths.

\section{Phase-transitions characterization}

The thermal behavior of NFT1 investigated by polarized optical microscopy (POM) revealed liquid crystalline properties. On heating, the crystalline solid melts to a birefringent fluid at $107{ }^{\circ} \mathrm{C}$, remaining in this phase until $118{ }^{\circ} \mathrm{C}$ where there is a transition to the isotropic liquid. On cooling from the liquid state a fan-shaped texture ${ }^{46}$ is observed in Figure 1a which is strong indication of a Smectic mesophase A (SmA). ${ }^{28,47}$ In this liquid crystalline phase, molecules are arranged in layers, oriented on average parallel to the layer normal as illustrated in Figure 1d, suggesting their capability of lateral packing and alignment. A similar molecule but with a phenyl ring instead of the naphthyl unit is not liquid crystalline, ${ }^{48}$ thus demonstrating the importance of the naphthyl unit for the desired properties. The thermogram in Figure 1b indicates the SmA mesophase between the crystalline (Cr) and isotropic liquid phases (Iso), both on heating and cooling, corroborating the POM analysis. A representation of transitions with corresponding temperatures is given in Figure 1c. From the DSC, the enthalpy of the SmA-Iso and Iso-SmA transitions was calculated as $3.5 \mathrm{~kJ} \mathrm{~mol}^{-1}$, as expected for this type of transition. Therefore, the fan-shaped texture, the low transition enthalpy values, low thermal hysteresis for SmA-Iso and Iso-SmA transitions confirm the liquid crystallinity of NFT1, more precisely a SmA phase. ${ }^{46}$

\section{Langmuir films characterizations}

In addition to the self-assembly characteristics described above, NFT1 is amphiphilic and could be studied in a Langmuir trough. The surface pressure-area (П-A) isotherm for NFT1 in Figure 2a is typical of an amphiphile with an average area per molecule of $\mathrm{A}=41 \AA^{2}$ in the condensed phase. The compound RuNFT1 also exhibited a typical isotherm of an amphiphile in Figure 2b, but
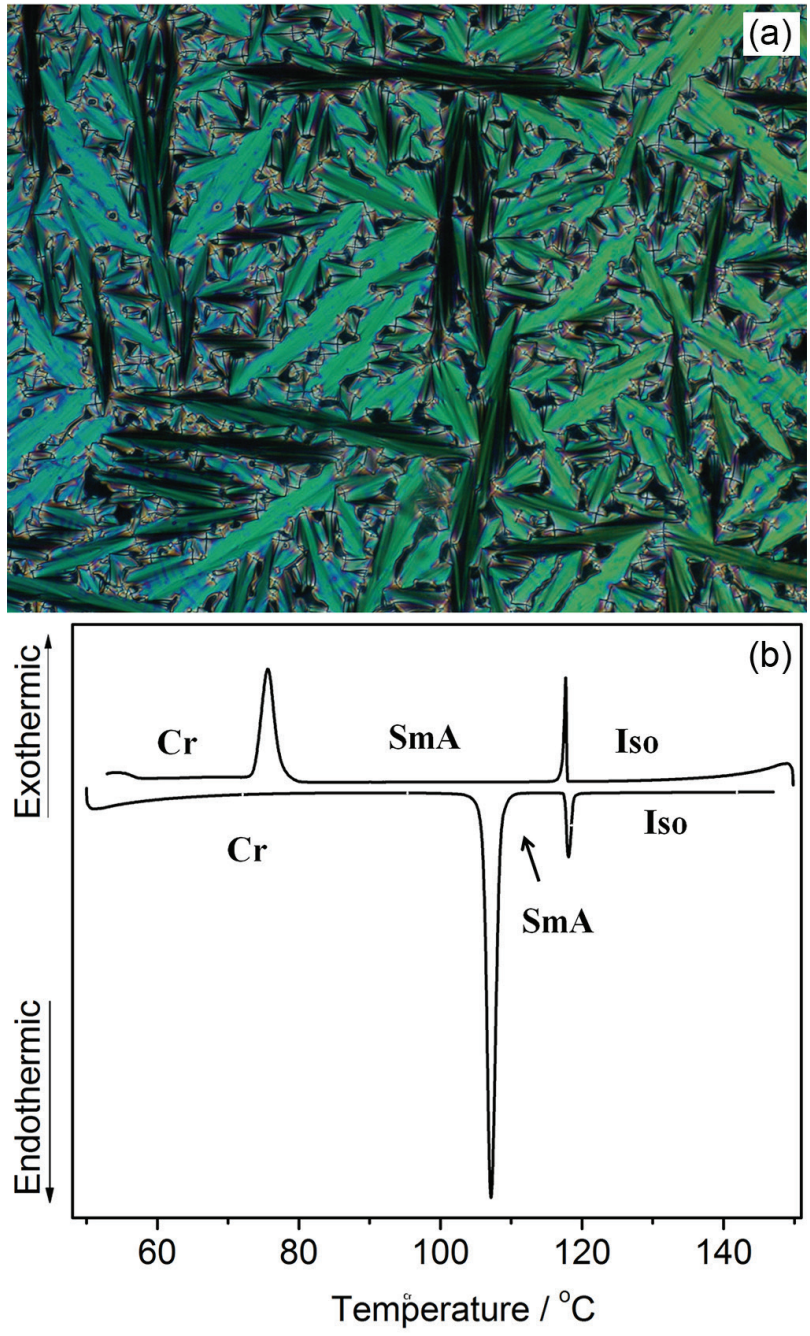

(c)

(d)
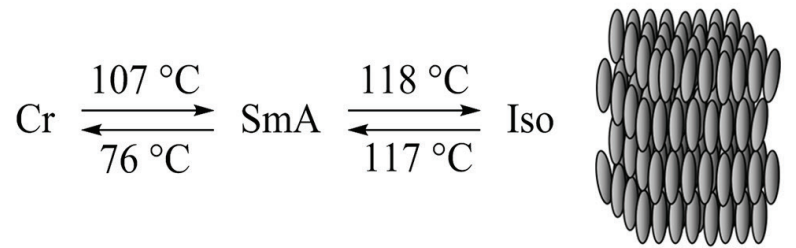

Figure 1. (a) POM image took at $117^{\circ} \mathrm{C}$ for NFT1 with the characteristic pattern of the fan-shaped ${ }^{46}$ texture of a Smectic-A mesophase $(\times 200)$. (b) DSC thermogram for NFT1 at the first heating/cooling cycle. Rate heating/cooling $=10{ }^{\circ} \mathrm{C} \mathrm{min}{ }^{-1}$ under nitrogen atmosphere $\left(50 \mathrm{~mL} \mathrm{~min}{ }^{-1}\right.$ flow). (c) Illustration summarizing the thermal transitions for NFT1. (d) Molecular organization in a SmA phase.

the area per molecule was $\mathrm{A}=79 \AA^{2}$ owing to the large $\left[\mathrm{Ru}(\mathrm{bpy})_{2} \mathrm{Cl}\right]$ group linked to the $\mathrm{N}$-pyridyl unit of NFT1 . The PM-IRRAS spectrum for NFT1 in Figure 2c-black line shows downward bands for $v_{\mathrm{as}} \mathrm{CH}_{2}$ and $v_{\mathrm{s}} \mathrm{CH}_{2}$ at 2920 and $2858 \mathrm{~cm}^{-1}$, respectively, thus indicating that the transition dipole moments are oriented perpendicular to the aqueous surface, ${ }^{49}$ despite the low intensity of the signals. The wavenumbers coincide with those in the powder spectrum 
in Figure S10 and are consistent with DFT calculations in Table S4 in the SI section. The bands for $v C C$ at $1527 \mathrm{~cm}^{-1}$ and $v \mathrm{COC}$ at $1222 \mathrm{~cm}^{-1}$ in Figure 2d-black line are upward, i.e., these vibrations are parallel to the aqueous surface..$^{49}$ Hence, from the PM-IRRAS results we infer that NFT1 molecules have the $\mathrm{N}$-pyridine oriented towards the waterair interface and, because of the tilt angle at the naphtyl ether, the $\mathrm{C}_{12} n$-alkyl chains are oriented closer to the plane of the water surface, as depicted in Scheme 3. The PMIRRAS spectrum for RuNFT1 in Figure 2c-red line shows a downward band at $2916 \mathrm{~cm}^{-1}\left(v_{\mathrm{as}} \mathrm{CH}_{2}\right)$ and a shoulder at $2852 \mathrm{~cm}^{-1}$ corresponding to $v_{\mathrm{s}} \mathrm{CH}_{2}$. Figure $2 \mathrm{~d}$-red line shows an upward band for $\mathrm{VCOC}$ at $1207 \mathrm{~cm}^{-1}$. Therefore, RuNFT1 probably has the same orientation as NFT1 at the liquid-air interface, but with lower degree of organization since the PM-IRRAS bands are less defined. In fact, the FTIR spectrum of the NFT1 powder contains intense, narrow bands, whilst broad bands are seen in the RuNFT1 spectrum, indicating the tendency of NFT1 molecules to self-assemble, since a high molecular organization tendency is already present for the solid NFT1.

NFT1 and RuNFT1 monolayers were also characterized by BAM at several surface pressures, and selected BAM images for NFT1 are shown in Figure 3. At $\Pi=0 \mathrm{mN} \mathrm{m}^{-1}$, corresponding to gaseous phase region, NFT1 assembles in a homogeneous film, as the image does not present bright regions or domains. The continuous, homogeneous surface is maintained as the surface pressure increases. The image at $29 \mathrm{mN} \mathrm{m}^{-1}$, close to the liquid-condensed region, shows low contrast indicating a very homogeneous surface due to high molecular organization and packing. ${ }^{50}$ Only after the collapse pressure, well defined structures are observed, which are consistent with overlap of multiple layers (Figure 3, $41 \mathrm{mN} \mathrm{m}^{-1}$ ). The BAM results confirm the high molecular organization of NFT1 indicated by the PM-IRRAS and POM results.

A very distinct behavior was observed for the Langmuir films of RuNFT1 in Figure 4. The BAM image taken at
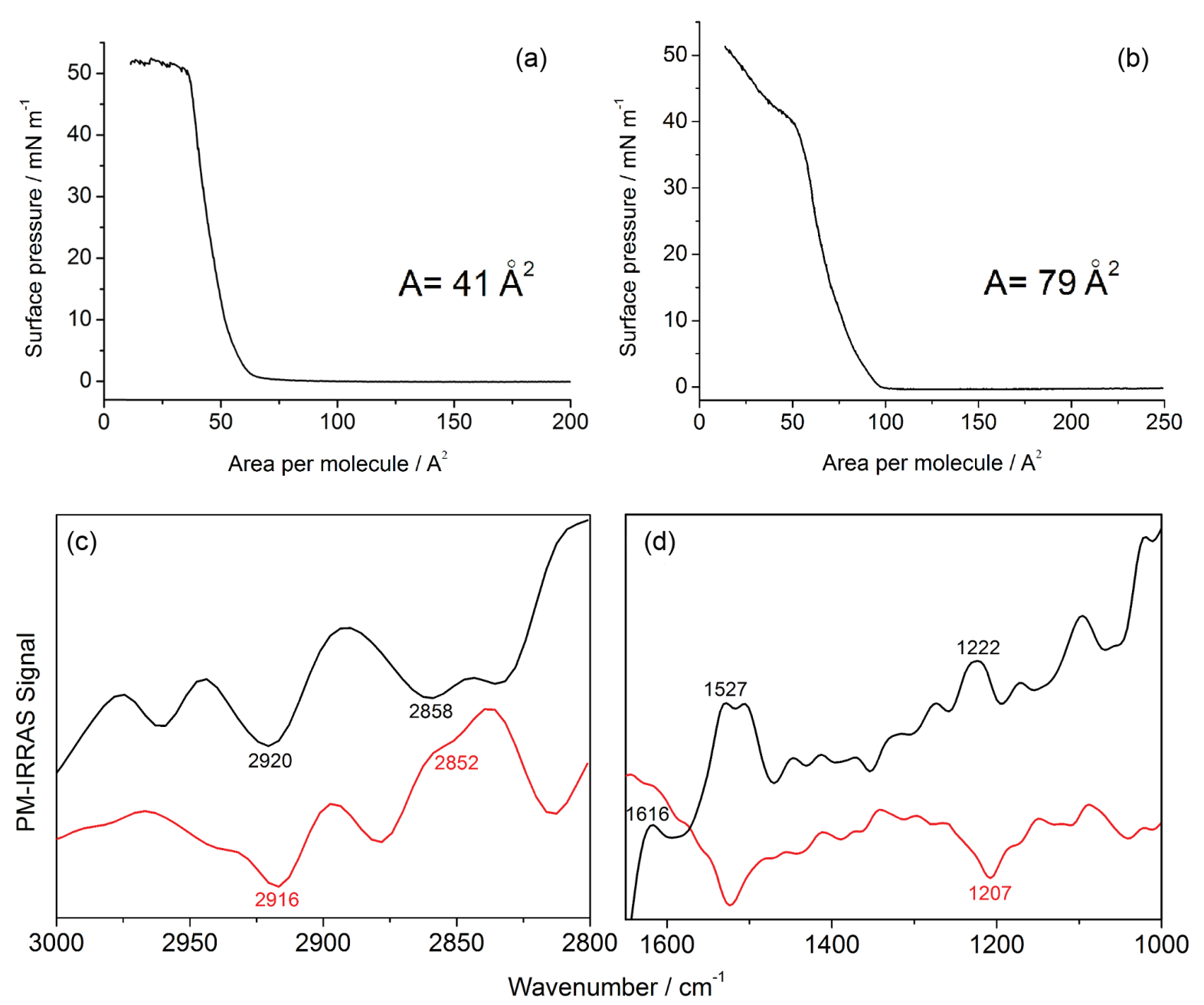

Figure 2. П-A isotherms for (a) NFT1 and (b) RuNFT1. Barrier speed $=100 \mathrm{~cm}^{2} \mathrm{~min}^{-1}$. Experimental details are described in the Experimental section. PM-IRRAS spectra for NFT1 (black line) at $\Pi=29 \mathrm{mN} \mathrm{m}^{-1}$ and RuNFT1 (red line) at $\Pi=21 \mathrm{mN} \mathrm{m}^{-1}$ for $v(\mathrm{CH})$ (c) and $v(\mathrm{CC})$ and $v(\mathrm{CO})$ (d) IR regions. Note: wavenumber above the line = upward band; wavenumber below the line $=$ downward band. 


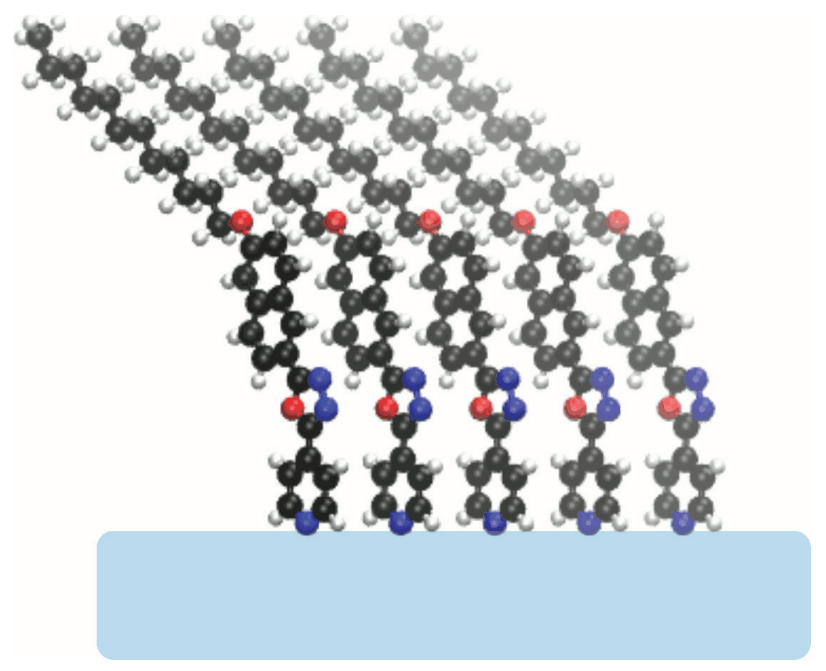

Scheme 3. Scheme of NFT1 Langmuir monolayer. $\mathrm{C}_{12} n$-alkyl chains are oriented closer to the plane of the water surface and naphotoxazole rings interacts face-to-face in the aggregate.

$\Pi=0 \mathrm{mN} \mathrm{m}^{-1}$ already shows striated structures with high contrast, indicating multilayer domains consisting of fibrils at the gas phase. ${ }^{51}$ As the surface pressure increased to reach the liquid-expanded region, a continuous, homogenous film was formed with the images showing low contrast at 2.0 and $9.7 \mathrm{mN} \mathrm{m}^{-1}$. As the liquid-condensed phase was reached, the image became brighter, probably as a result of increased film thickness due to the closer packing of the molecules. At
$\Pi=28.7 \mathrm{mN} \mathrm{m}^{-1}$ in the condensed phase, a homogeneous film was observed. Rough textures indicated by the arrow in Figure 4 suggest the collapse of the film in some regions.

\section{Solid LB films characterizations}

The IRRAS spectra for LB films of NFT1 and RuNFT1 deposited on gold substrates in Figures S10-S11 show more intense signals for the $s$ - than for the $p$-polarization. The preferential orientation with aliphatic chains close to the normal plane at the liquid-air interface is probably retained on the gold substrates. In this case the symmetric and antisymmetric $\mathrm{CH}_{2}$ stretchings are $s$-polarized, being responsible for the higher intensity in this polarization. ${ }^{52,53}$ In addition, the bands in the LB films are better defined than the powder spectrum, probably owing to more molecules aligned in the same direction in the LB film.

The UV-Vis spectra of the LB films deposited on quartz substrates and the compounds dissolved in dichloromethane are shown in Figures 5a-5b. Dramatic changes in the UV-Vis spectrum were observed in the 20-monolayer LB film compared to the solution spectrum of NFT1 (Figure 5a). These changes in the intensity and energy of the $\pi-\pi^{*}$ transitions were assigned to aggregation between naphtooxadiazole chromophores due to the film deposition process. Scheme 3 depicts the NFT1 monolayer

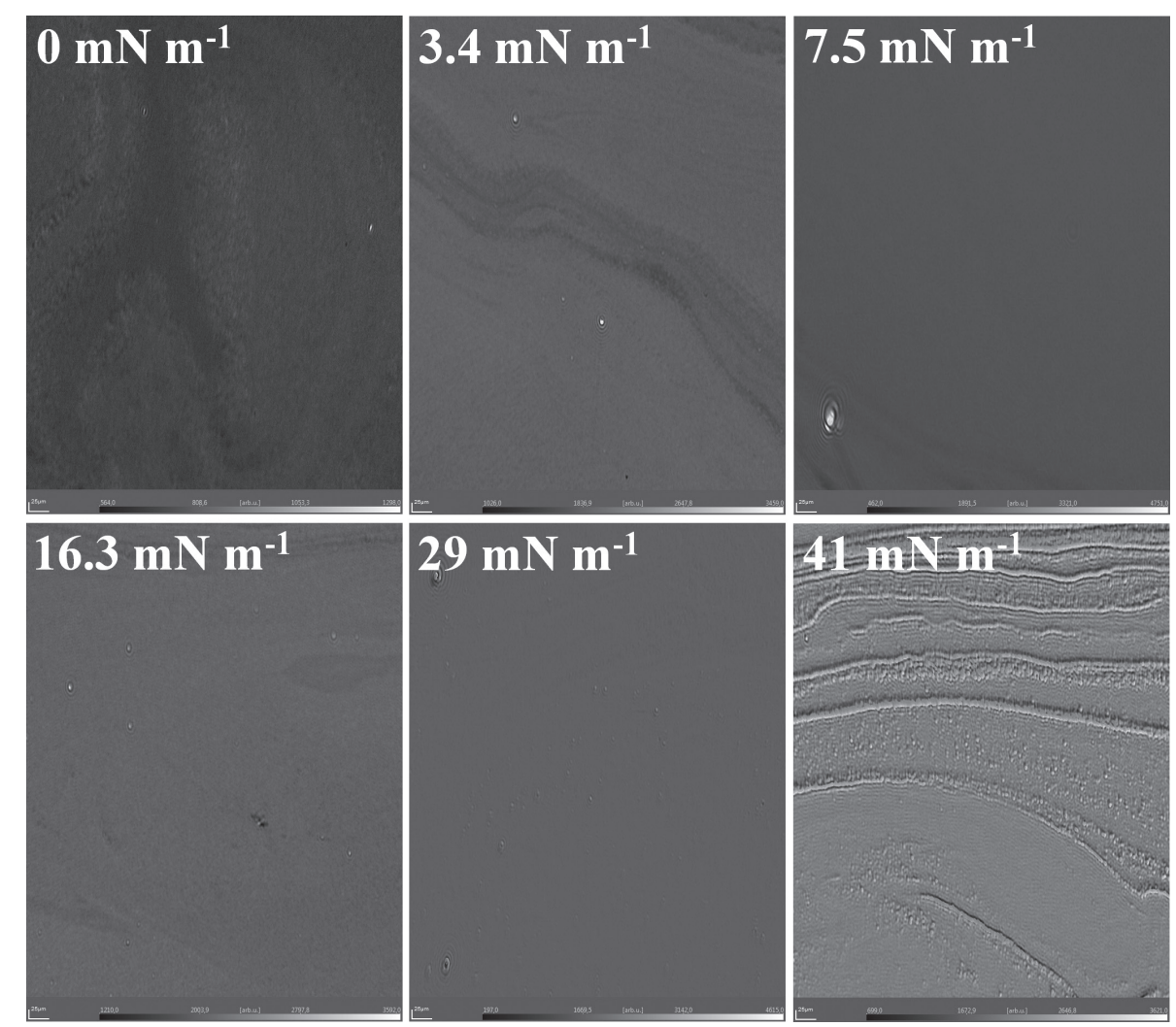

Figure 3. Selected BAM images for NFT1 at several surface pressures. $\Pi$ is indicated at the images. 

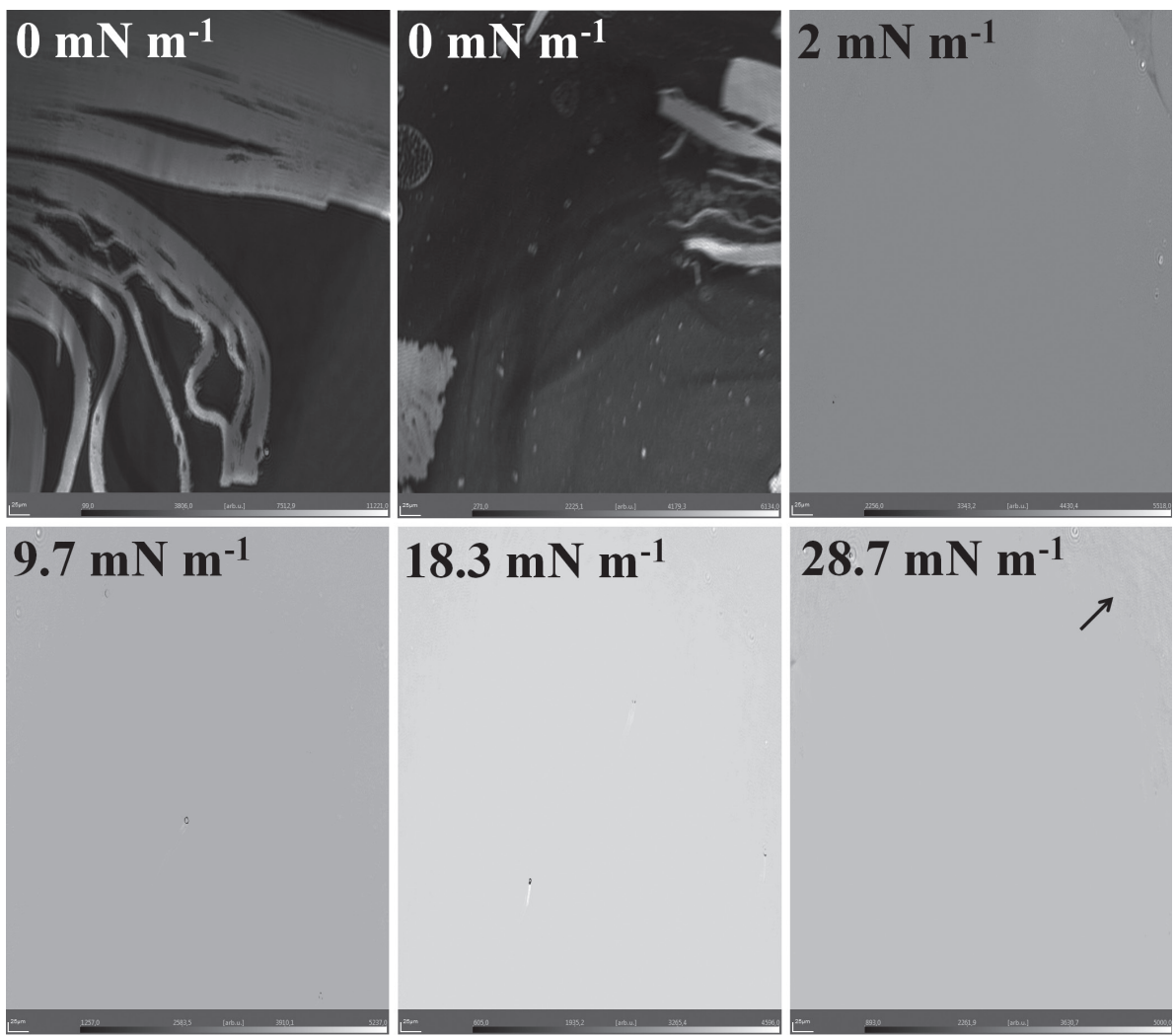

Figure 4. Selected BAM images for RuNFT1 at several surface pressures. $\Pi$ is indicated at the images. The arrow points to some rough textures that suggest collapse.

formation. When the NFT1 molecules aggregate in the liquid-air interface, the naphtoxadiazole groups of neighbor molecules become closer to each other and the face-to-face interaction is responsible for the hypsochromic shifts ${ }^{54}$ observed. However, Figure 5b shows similar spectra with small shifts for RuNFT1 20-monolayer LB film and dichloromethane solution. In this case, since RuNFT1 exhibits similar assembly at the liquid-air interface, the large ruthenium residue should preclude aggregation between naphtooxadiazole groups, preserving the UV-Vis spectrum profile for the LB film.

\section{Electrochemistry}

Molecular organization affects the electrochemical behavior of films, since a densely packed structure may
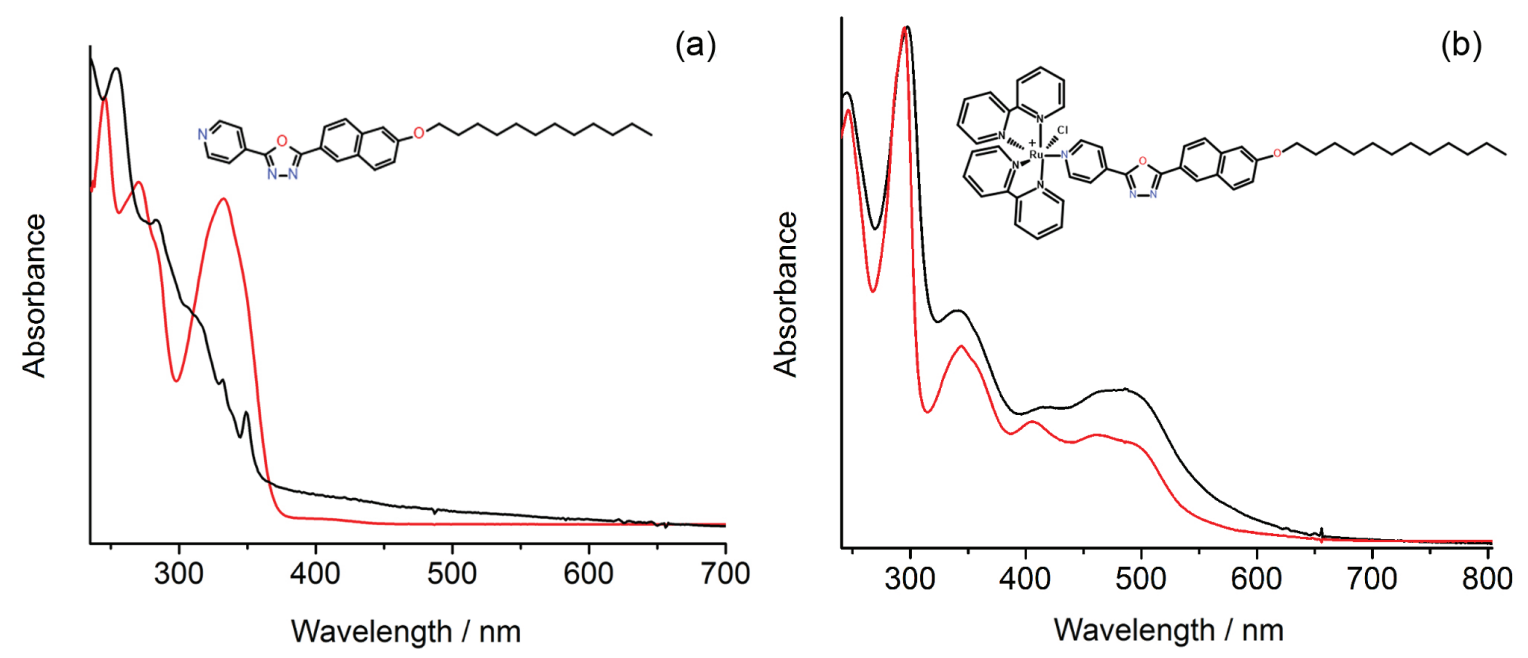

Figure 5. UV-Vis spectra of the compounds in (red line) $\mathrm{CH}_{2} \mathrm{Cl}_{2}$ solution and (black line) as 20-monolayer LB film. (a) NFT1 and (b) RuNFT1. Absorption intensities were normalized for better visualization. 
hinder ion intercalation and diffusion through the film, but it could also promote electron diffusion owing to $\pi-\pi^{*}$ interaction of aligned molecules. Here, we investigated the electrochemical properties of three types of systems: 9-monolayer LB film of NFT1, 9-monolayer LB film of RuNFT1 and a heterostructured film made by a 9-monolayer NFT1 LB film coated with a single LB monolayer of RuNFT1. The composition of the heterostructured film was chosen based on our previous study, ${ }^{26}$ in which we determined optimized conditions of controlled deposition and efficient charge hopping process. With 9 monolayers the LB film is sufficiently thin to guarantee an open structure, allowing ionic diffusion within the film. We chose only one monolayer of the RuNFT1 redox active film in order to explore the maximum efficiency of the Faradaic charge storage of this material. The LB films were studied by cyclic voltammetry (CV) and charge-discharge (CD) chronopotentiometry to test them as electrodes for energy storage. The voltammogram for the NFT1 LB film in Figure $6 \mathrm{a}$ is roughly rectangular and the charge-discharge profile is triangular (Figure $6 \mathrm{c}$ ), thus indicating a capacitive behavior $^{8,55,56}$ associated with the formation of an electrical double layer. At potentials lower than $0.4 \mathrm{~V}$ the cathodic current increased slightly, especially at low scan rates and discharge currents (see Figure S12). This is probably caused by the ion diffusion required for charge neutrality through the film at these bias potentials. The voltammogram for RuNFT1 has a redox peak with $\mathrm{E}_{1 / 2}=0.987 \mathrm{~V}$ and the CD profile is curved at potentials higher than $0.8 \mathrm{~V}$. These features are attributed to the $\mathrm{Ru}^{\mathrm{III} / \mathrm{II}}$ process. At potentials lower than $0.8 \mathrm{~V}$ the voltammogram is rectangular, similar to those for NFT1, but with lower currents. The CD profile is linear, but with higher slope than for NFT1. These results indicate that the RuNFT1 LB film has a smaller electrical double layer capacitance.

The capacitance was determined using EIS data as proposed by Taberna et $a l .{ }^{57}$ who assumed the system as a single large capacitor. Figure $6 \mathrm{~b}$ shows the plot of the real part of the impedance as a function of the frequency. At low frequencies, the real part of the impedance corresponds to the capacitance of the cell during discharge at constant currents. ${ }^{57}$ The capacitance of RuNFT1 film at $0.21 \mathrm{~V}$ is significantly lower (Figure 6b-empty green circles) than for the other films, whereas at $1.06 \mathrm{~V}$ (Figure 6b-solid green circles) the capacitance is increased by approximately three times, being higher than for the other films due to $\mathrm{Ru}^{\mathrm{III} / \mathrm{II}}$ redox processes. This change in capacitance in the RuNFT1 film indicates that it behaves as a battery-like material since it cannot be represented as a single capacitor in the potential range studied..$^{55,56}$ The heterostructured LB film exhibits a redox peak with $\mathrm{E}_{1 / 2}=0.975 \mathrm{~V}$ assigned to the
$\mathrm{Ru}^{\mathrm{III/II}}$ process, but the peak current is less intense than for RuNFT1 film as a consequence of the lower electroactive surface concentration. At potentials lower than $0.8 \mathrm{~V}$ the voltammogram is rectangular, exhibiting capacitive currents similar to those for the NFT1 film. The CD profile was almost triangular with a slight feature from 0.9 to $1.0 \mathrm{~V}$, and the slopes of charge and discharge are closer to those of NFT1 film. This confirms that the capacitive currents are similar to those for NFT1. Comparing the capacitances determined at low frequencies at $0.21 \mathrm{~V}$ (empty black squares) with at $1.06 \mathrm{~V}$ (solid black squares) we noticed only a slight increment at $1.06 \mathrm{~V}$, which is likely the result from the contribution of ruthenium sites in the heterostructured film. The shape of the voltammogram and the small variation in capacitance with the potential suggest that the heterostructured film acts as a capacitor. ${ }^{55,56}$

The potential peak separation in the heterostructured film is remarkably small $(\Delta \mathrm{E}=0.03 \mathrm{~V})$ even at scan rates as high as $400 \mathrm{mV} \mathrm{s}^{-1}$, while the peak currents are proportional to the scan rate (Figure S13a). These results reveal the highly effective redox property of the heterostructured film, since the assembly of this film promotes synergy between the highly ordered NFT1 film, which creates electron and ionic diffusion paths and contributes with electron hopping, ${ }^{26}$ and the RuNFT1 monolayer on the top. The latter exposes the electroactive ruthenium sites at the interface with the electrolyte solution. The pure RuNFT1 film, on the other hand, exhibited a larger potential peak separation $\left(\Delta \mathrm{E}=0.1 \mathrm{~V}\right.$ at $\left.400 \mathrm{mV} \mathrm{s}^{-1}\right)$, and the current peak intensities $v s$ scan rate plot deviates from linearity, especially at higher scan rates (Figure $\mathrm{S} 13 \mathrm{~b}$ ). This reveals a diffusion-limited process due to the distribution of electroactive sites along the film thickness. Since the less organized RuNFT1 film should have the charge diffusion resistance increased, it displayed a more resistive and less capacitive behavior.

The electrochemical processes in these LB films were further investigated by electrochemical impedance spectroscopy (EIS) at two bias potentials (0.21 and $1.06 \mathrm{~V})$. The Nyquist plots in Figure 7 can be divided into three regions: at high frequencies, where the electrical conductivity (ionic and electronic) dominates; at middle frequencies, where an arc line is associated to charge transport with a resistive element due to movement of ions and electrons across the film and a capacitive element due to charge separations; and at low frequencies, where a sharp increment in the imaginary impedance results in an almost vertical line due to low frequency processes and the establishment of a capacitance. The Nyquist plot at $0.21 \mathrm{~V}$ is depicted in Figure 7a, with the RuNFT1 film (green circles) displaying the steeper rise of imaginary impedance at low frequencies (from $166 \mathrm{~Hz}$ to $0.1 \mathrm{~Hz}$ ). This was attributed 

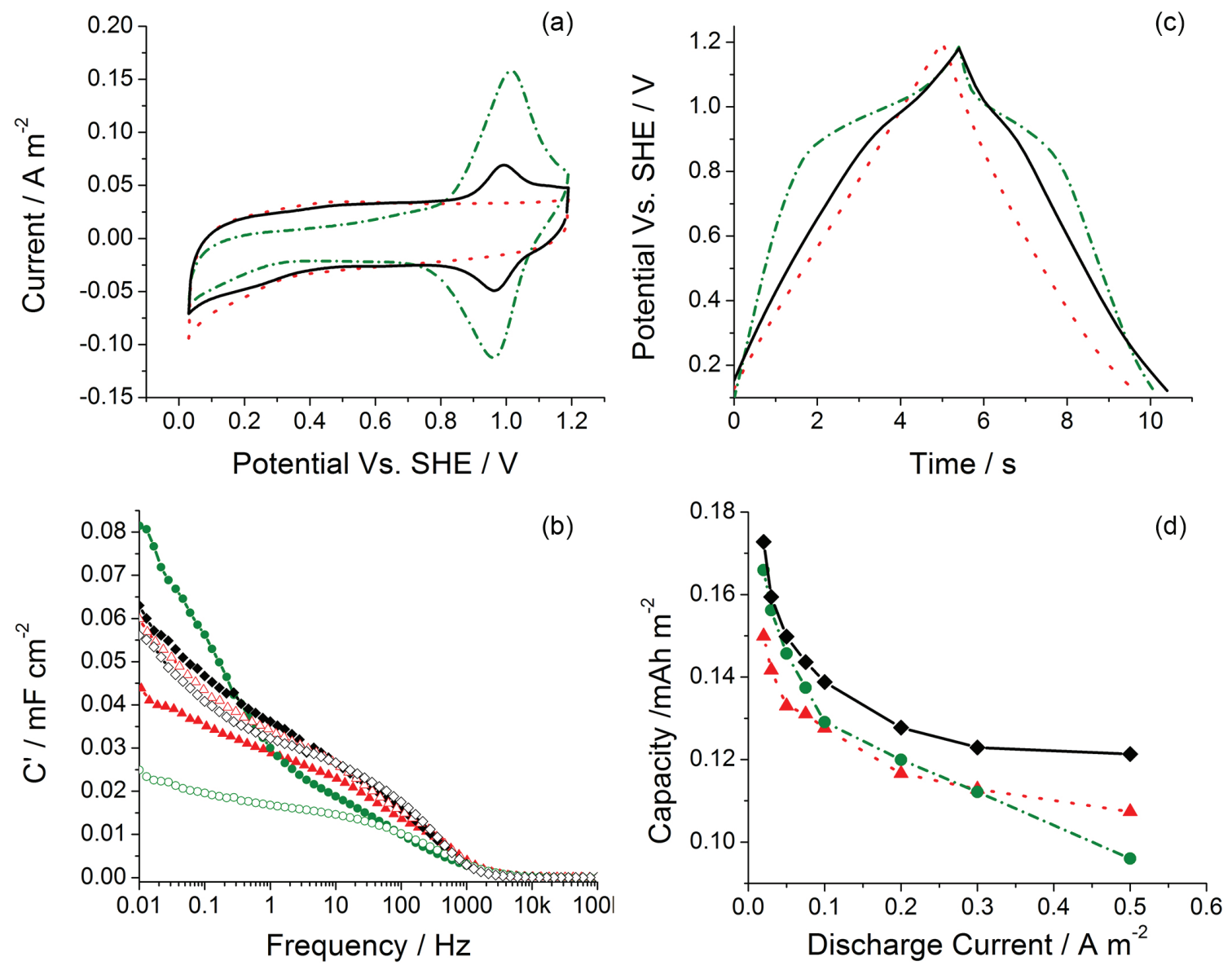

Figure 6. Electrochemical characterization of LB films. (a) Cyclic voltammograms of NFT1 (dotted red line), RuNFT1 (dashed green line), and heterostructured (solid black line) LB films. (b) Capacitance calculated from EIS of NFT1 (red), RuNFT1 (black) and heterostructured LB films (green) at $1.06 \mathrm{~V}$ (solid symbols) and $0.21 \mathrm{~V}$ (empty symbols) ( $v$ s SHE). (c) Charge-discharge curves for NFT1, RuNFT1 and heterostructured LB films. (d) Capacity calculated from discharge tests at several specific discharge currents for NFT1 (red triangles), RuNFT1 (black squares) and heterostructured LB films (green circles).
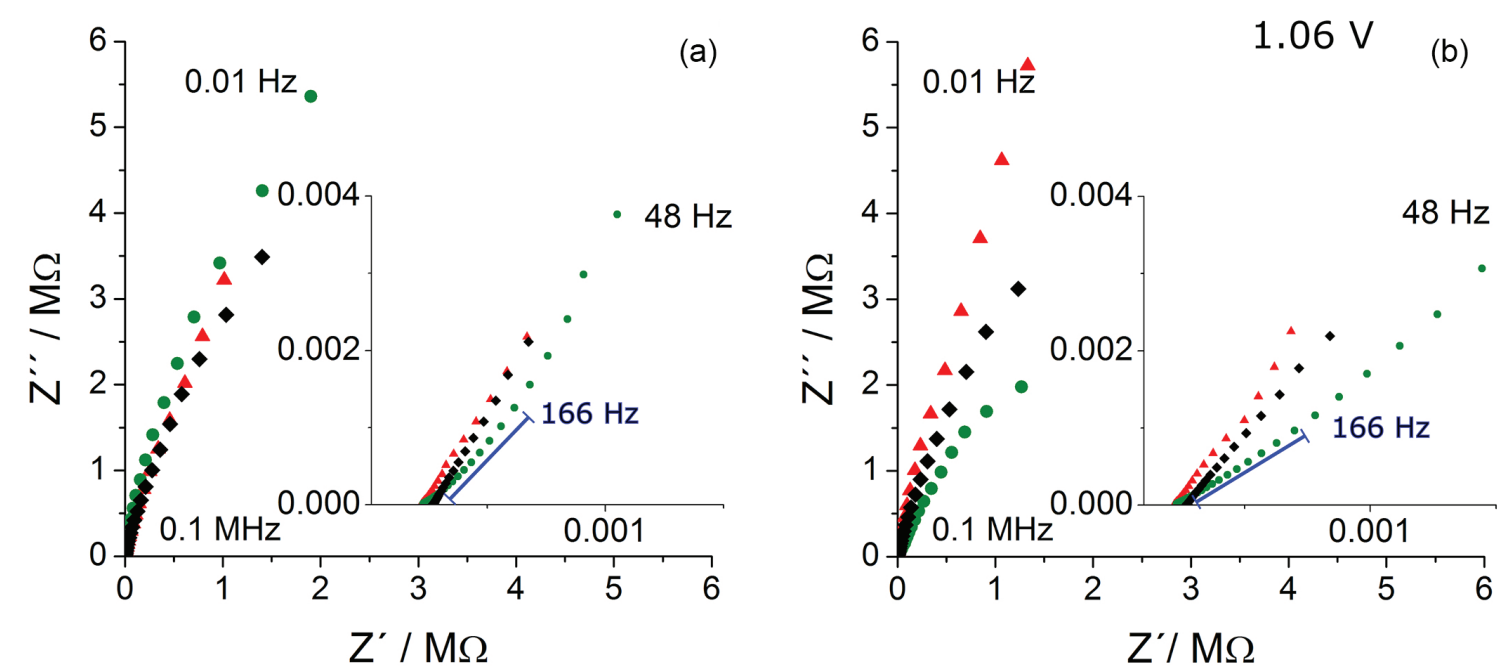

Figure 7. Electrochemical impedance spectroscopy (EIS) of LB films. (a) Nyquist plot at $0.21 \mathrm{~V}$ and (b) $1.06 \mathrm{~V}$ (red triangles) for NFT1 (green circles) RuNFT1, and (black squares) heterostructured LB films. Experiments were carried out from $10^{5} \mathrm{~Hz}$ to $0.1 \mathrm{~Hz}$. Inset: high frequency region expanded.

to a faster establishment of an electrical double layer. The Nyquist plots of NFT1 and heterostructured films (Figure 7a-red triangles and black squares) are similar since their capacitive behavior is dominated by the highly ordered NFT1 films. As for the Nyquist plots at $1.06 \mathrm{~V}$, the slopes are less steep for RuNFT1 and heterostructured 
films, particularly for RuNFT1. At $1.06 \mathrm{~V}$ the redox process $\mathrm{Ru}^{\mathrm{III} / \mathrm{II}}$ occurs, which increases the resistive component. A similar effect was reported for another redox material used as supercapacitor. ${ }^{58} \mathrm{~A}$ pronounced arc for RuNFT1 and a discrete one for heterostructured film are observed at low frequencies, consistent with the resistance due to the redox reaction, being less prominent for the heterostructured film. The insets in Figures $7 \mathrm{a}$ and $7 \mathrm{~b}$ show the results for intermediate frequencies (up to $166 \mathrm{~Hz}$ ) where the smallest slope was observed for the RuNFT1 film as its conductivity was the most limited by ion transport. ${ }^{59}$ The transition from the mass-transport limited region to the low frequency capacitive region is observed at relative high frequencies (around $166 \mathrm{~Hz}$ ), possibly due to the film thickness of a few molecular layers. In fact, a similar trend has been reported for ultrathin films. ${ }^{60}$ The estimated capacitances are 30.8 , 28.2 and $31.3 \mathrm{~F} \mathrm{~g}^{-1}$ at $0.02 \mathrm{~A} \mathrm{~m}^{-2}$ (it is ca. $1.1 \pm 0.1 \mathrm{~A} \mathrm{~g}^{-1}$ ) specific discharge current, for NFT1, RuNFT1 and heterostructured films, respectively. These values are lower than the reported of other pseudo-capacitor materials (metal oxides, conducting polymers and composites) tested on neutral electrolyte, such as $231 \mathrm{~F} \mathrm{~g}^{-1}$ for $\mathrm{RuO}_{2},{ }^{61} 188 \mathrm{~F} \mathrm{~g}^{-1}$ for graphene oxide/ $\mathrm{MnO}_{2}$, ${ }^{62}$ and from 78 to $261 \mathrm{~F} \mathrm{~g}^{-1}$ for polyaniline. ${ }^{63}$ Many factors influence the capacitance achieved in that electrodes, such as microstructure, porosity and the number of redox sites per mass unit. Variations in materials synthesis conditions are searched to optimize those factors. Our storage electrodes reached capacitance values closer to other ruthenium based materials. Kaliginedi et al. ${ }^{16}$ reported a capacitance value $=96 \mathrm{~F} \mathrm{~g}^{-1}$ for a dinuclear ruthenium complex multilayer film, but their experiments were performed in organic and acid electrolyte conditions which often lead to better performance, and the potential range in the work window tested contain two Faradaic processes for the dinuclear ruthenium complex. Furthermore, the capacitance values found in the present work are also higher than the $16 \mathrm{~F} \mathrm{~g}^{-1}$ registered for a triruthenium cluster modified graphene in neutral solution conditions (data not shown). Despite the small values of capacitance compared to other robust materials, the proof of concept demonstrates the use of components molecularly designed for the purpose. Capacitance improvements may be reached varying the layers composition of the heterostructured film, by increase porosity and optimizing the conditions of the electrolyte solution.

In summary, NFT1 and the heterostructured films have a capacitive behavior, but the latter one displayed a higher performance with the additional contribution of the redox RuNFT1 monolayer, without the resistive behavior of a RuNFT1 film. Scheme 4 depicts the heterostructured film and the contributions of NFT1 and RuNFT1 layers to the total capacitance of the electrode. Although the estimated capacitance at $0.02 \mathrm{~A} \mathrm{~m}^{-2}$ for the heterostructured has a small increment than the NFT1 film, the heterostructured film exhibits higher capacitances at all discharge currents tested, as shown in Figure 6d. The RuNFT1 film exhibited higher capacity associated with the Faradaic contribution, but the capacity owing to the double layer is significantly lower than for the other films. Consequently, the capacitance of the RuNFT1 film at the discharge currents tested was lower than for the heterostructured film (Figure 6d), since the Faradaic contribution does not exceed the electric double-layer contribution in the heterostructured film. In addition, RuNFT1 exhibited a significant decrease in capacitance at higher discharge currents, reaching values lower than that for NFT1 film, which could be associated with the ion transport to active sites along the film thickness.

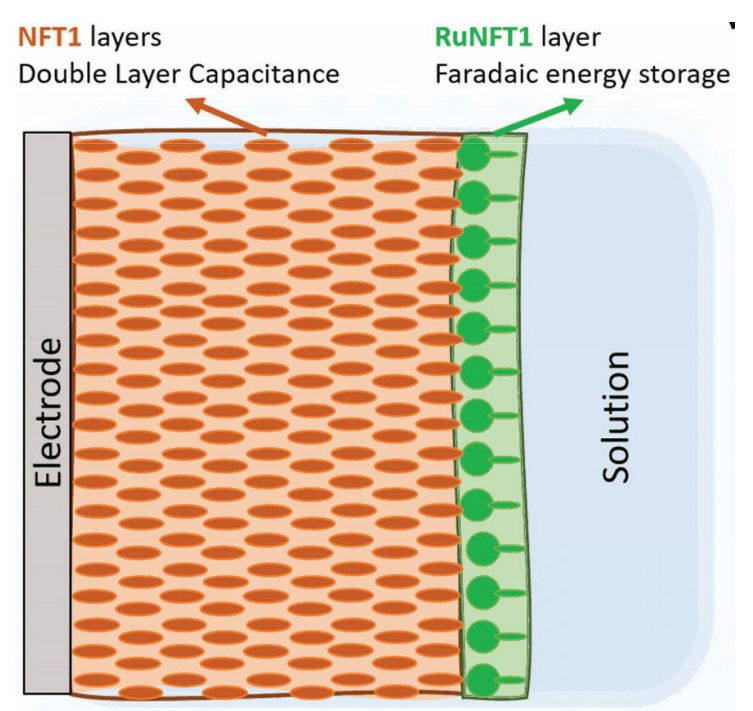

Scheme 4. Heterostructured film and the contributions of NFT1 and RuNFT1 layers to the capacitance of the electrode.

\section{Conclusions}

This study was aimed at applying molecular design principles with LB films for charge storage electrodes, in which the synergy among distinct materials and the ability of molecular-level control for packing were explored. First, molecular self-assembly of NFT1 was afforded by the naphthyl group yielding planarity to the chromophore region, as inferred from the DFT geometry optimization. The fact that compound NFT1 shows a liquid crystalline behavior and a SmA phase demonstrates the strong ability of this material to promote parallel alignment, which is important for a good lateral packing at the liquid-air interface and for the multilayer LB film formation. With the nature of NFT1, organized LB films could be produced but these films were unlikely to serve as charge storage 
materials. We then resorted to the redox-active derivative RuNFT1 with NFT1 bonded to the $\left[\mathrm{Ru}(\mathrm{bpy})_{2} \mathrm{Cl}\right]^{+}$residue, which could also form LB films but whose order was not as high as for the neat NFT1 LB films. In order to combine the desired characteristics of film organization and redox activity, we produced a heterostructured LB film with 9 layers of NFT1 coated with 1 layer of RuNFT1. Under optimized conditions, this heterostructured film exhibited charge storage characteristics due to the double layer capacitance from the NFT1 multilayer and the Faradaic capacitance from RuNFT1. Our results also demonstrate that the tailoring of molecular films composed of capacitive and electroactive layers are a feasible way to develop efficient supercapacitor electrodes.

\section{Supplementary Information}

Supplementary data are available free of charge at http://jbcs.sbq.org.br as PDF file.

\section{Acknowledgments}

The authors thank the following institutions for financial support: FINEP, UFPR, UTFPR, INCT-INEO, CAPES, CNPq and FAPESP (2013/14262-7). The authors are also grateful to CEBIME-UFSC for the HRMS analysis, Hugo Gallardo, Alceu Totti Silveira Junior.

\section{Author Contributions}

Herbert Winnischofer was responsible for conceptualization, formal analysis funding acquisition, project administration, resources, writing-review and editing; Elizangela Cavazzini Cesca for conceptualization, data curation, investigation, writing original draft, writingreview and editing; Alejandro E. Pérez Mendoza for data curation, software, writing-review; Eduard Westphal for resources, formal analysis funding acquisition, writingreview and editing; Daniela Z. Mezalira for data curation; Iolanda Ponzetta Araújo for data curation; Débora T. Balogh for data curation; Osvaldo N. Oliveira Jr. for formal analysis funding acquisition, resources, writingreview and editing.

\section{References}

1. Toma, H. E.; J. Braz. Chem. Soc. 2003, 14, 845.

2. Toma, H. E.; Curr. Sci. 2008, 95, 1202.

3. Toma, H. E.; Araki, K.; Prog. Inorg. Chem. 2009, 56, 380.

4. Dong, L.; Xu, C.; Li, Y.; Huang, Z. H.; Kang, F.; Yang, Q. H.; Zhao, X.; J. Mater. Chem. A 2016, 4, 4659.
5. Peng, X.; Peng, L.; Wu, C.; Xie, Y.; Chem. Soc. Rev. 2014, 43, 3303.

6. Wang, F.; Wu, X.; Yuan, X.; Liu, Z.; Zhang, Y.; Fu, L.; Zhu, Y.; Zhou, Q.; Wu, Y.; Huang, W.; Chem. Soc. Rev. 2017, 46, 6816.

7. Yan, J.; Wang, Q.; Wei, T.; Fan, Z.; Adv. Energy Mater. 2014, 4, 1300816.

8. Brousse, T.; Bélanger, D.; Chiba, K.; Egashira, M.; Favier, F.; Long, J.; Miller, J. R.; Morita, M.; Naoi, K.; Simon, P.; Sugimoto, W. In Springer Handbook of Electrochemical Energy; Breitkopf, C.; Swider-Lyons, S., eds.; Springer: HeidelbergBerlin, 2017, ch. 16.

9. González, A.; Goikolea, E.; Barrena, J. A.; Mysyk, R.; Renewable Sustainable Energy Rev. 2016, 58, 1189.

10. Snook, G. A.; Kao, P.; Best, A. S.; J. Power Sources 2011, 196, 1.

11. Shown, I.; Ganguly, A.; Chen, L. C.; Chen, K. H.; Energy Sci. Eng. 2015, 3, 1.

12. Augustyn, V.; Simon, P.; Dunn, B.; Energy Environ. Sci. 2014, 7, 1597.

13. Meng, Q.; Cai, K.; Chen, Y.; Chen, L.; Nano Energy 2017, 36, 268.

14. Lokhande, V. C.; Lokhande, A. C.; Lokhande, C. D.; Kim, J. H.; Ji, T.; J. Alloys Compd. 2016, 682, 381.

15. Zhi, M.; Xiang, C.; Li, J.; Li, M.; Wu, N.; Nanoscale 2013, 5, 72.

16. Kaliginedi, V.; Ozawa, H.; Kuzume, A.; Maharajan, S.; Pobelov, I. V.; Kwon, N. H.; Mohos, M.; Broekmann, P.; Fromm, K. M.; Haga, M. A.; Wandlowski, T.; Nanoscale 2015, 7, 17685.

17. Choi, K. M.; Jeong, H. M.; Park, J. H.; Zhang, Y. B.; Kang, J. K.; Yaghi, O. M.; ACS Nano 2014, 8, 7451.

18. Yu, M.; Feng, X.; Joule 2019, 3, 338.

19. Toma, H. E.; Araki, K.; Coord. Chem. Rev. 2000, 196, 307.

20. Winnischofer, H.; Otake, V. Y.; Dovidauskas, S.; Nakamura, M.; Toma, H. E.; Araki, K.; Electrochim. Acta 2004, 49, 3711.

21. Winnischofer, H.; Lima, S. S.; Araki, K.; Toma, H. E.; Anal. Chim. Acta 2003, 480, 97.

22. Winnischofer, H.; Engelmann, F. M.; Toma, H. E.; Araki, K.; Rechenberg, H. R.; Inorg. Chim. Acta 2002, 338, 27.

23. Araki, K.; Wagner, M. J.; Wrighton, M. S.; Langmuir 1996, 12, 5393.

24. Winnischofer, H.; Formiga, A. L. B.; Nakamura, M.; Toma, H. E.; Araki, K.; Nogueira, A. F.; Photochem. Photobiol. Sci. 2005, 4, 359.

25. Naidek, K. P.; Hoffmeister, D. M.; Pazinato, J.; Westphal, E.; Gallardo, H.; Nakamura, M.; Araki, K.; Toma, H. E.; Winnischofer, H.; Eur. J. Inorg. Chem. 2014, 1150.

26. Pazinato, J.; Hoffmeister, D. M.; Naidek, K. P.; Westphal, E.; Gallardo, H.; Winnischofer, H.; Electrochim. Acta 2015, 153, 574.

27. Paun, A.; Hadade, N. D.; Paraschivescu, C. C.; Matache, M.; J. Mater. Chem. C 2016, 4, 8596. 
28. Ferreira, M.; Westphal, E.; Ballottin, M. V.; Bechtold, I. H.; Bortoluzzi, A. J.; Mezalira, D. Z.; Gallardo, H.; New J. Chem. 2017, 41, 11766.

29. Gallardo, H.; Westphal, E.; Curr. Org. Synth. 2015, 12, 806.

30. Deshapande, N.; Belavagi, N. S.; Sunagar, M. G.; Gaonkar, S.; Pujar, G. H.; Wari, M. N.; Inamdar, S. R.; Khazi, I. A. M.; RSC Adv. 2015, 5, 86685.

31. Chen, R. T.; Su, W. F.; Chen, Y.; J. Polym. Sci., Part A: Polym. Chem. 2011, 49, 184.

32. Westphal, E.; da Silva, D. H.; Molin, F.; Gallardo, H.; RSC Advances 2013, 3, 6442.

33. Bolink, H. J.; Baranoff, E.; Clemente-León, M.; Coronado, E.; Lardiés, N.; López-Muñoz, A.; Repetto, D.; Nazeeruddin, M. K.; Langmuir 2010, 26, 11461.

34. Neese, F.; Wiley Interdiscip. Rev.: Comput. Mol. Sci. 2012, 2 , 73.

35. Neese, F.; Wiley Interdiscip. Rev.: Comput. Mol. Sci. 2018, 8, 4.

36. Weigend, F.; Ahlrichs, R.; Phys. Chem. Chem. Phys. 2005, 7 , 3297.

37. Weigend, F.; Phys. Chem. Chem. Phys. 2006, 8, 1057.

38. Grimme, S.; Antony, J.; Ehrlich, S.; Krieg, H.; J. Chem. Phys. 2010, 132.

39. Grimme, S.; Ehrlich, S.; Goerigk, L.; J. Comput. Chem. 2010 , 32.

40. Becke, A. D.; Phys. Rev. A 1988, 4, 276.

41. Perdew, J. P.; Phys. Rev. B 1986, 33, 8822.

42. Adamo, C.; Barone, V.; J. Chem. Phys. 1999, 110, 6158.

43. Sullivan, B. P.; Salmon, D. J.; Meyer, T. J.; Inorg. Chem. 1978, 17, 3334.

44. Lever, A. B. P.; Inorg. Chem. 1990, 29, 1271.

45. Cesca, E. C.; Hoffmeister, D. M.; Naidek, K.; Novo, J. B. M.; Serbena, J. P. M.; Hümmelgen, I. A.; Westphal, E.; Araki, K.; Toma, H. E.; Winnischofer, H.; Electrochim. Acta 2020, 136350.

46. Blinov, L. M.; Structure and Properties of Liquid Crystals; Springer US: New York, 2011.
47. Filippi, N. G.; Mezalira, D. Z.; Ovalle, S.; Westphal, E.; Liq. Cryst. 2016, 43, 2163.

48. Pedro, J. A.; Mora, J. R.; Westphal, E.; Gallardo, H.; Fiedler, H. D.; Nome, F.; J. Mol. Struct. 2012, 1016, 76.

49. Payan, S.; Desbat, B.; Langmuir 1996, 12, 6627.

50. Daear, W.; Mahadeo, M.; Prenner, E. J.; Biochim. Biophys. Acta 2017, 1859, 1749.

51. Vollhardt, D.; Adv. Colloid Interface Sci. 2018, 258, 36.

52. Tolstoy, V. P.; Chernyshova, I. V.; Skryshevsky, V. A.; Handbook of Infrared Spectroscopy of Ultrathin Films; John Wiley \& Sons: Hoboken, 2003.

53. Transferetti, B. C.; Davanzo, C. U.; Quim. Nova 2001, $24,99$.

54. Inglot, K.; Kaleta, A.; Martyński, T.; Bauman, D.; Dyes Pigm. 2008, 77, 303.

55. Conway, B. E.; Electrochemical Supercapacitors Scientific Fundamentals and Technological Applications; Springer: New York-Boston, 1999.

56. Brousse, T.; Bélanger, D.; Long, J. W.; J. Electrochem. Soc. 2015, 162, A5185.

57. Taberna, P. L.; Simon, P.; Fauvarque, J. F.; J. Electrochem. Soc. 2003, 150, A292.

58. Lukatskaya, M. R.; Kota, S.; Lin, Z.; Zhao, M.-Q.; Shpigel, N.; Levi, M. D.; Halim, J.; Taberna, P.-L.; Barsoum, M. W.; Simon, P.; Gogotsi, Y.; Nat. Energy 2017, 2, 17105.

59. Mei, B.-A.; Munteshari, O.; Lau, J.; Dunn, B.; Pilon, L.; J. Phys. Chem. C 2018, 122, 194.

60. Levi, M. D.; Aurbach, D.; J. Phys. Chem. B 1997, 101, 4630.

61. Xia, H.; Shirley Meng, Y.; Yuan, G.; Cui, C.; Lu, L.; Electrochem. Solid-State Lett. 2012, 15, A60.

62. Dong, X.; Wang, X.; Wang, J.; Song, H.; Li, X.; Wang, L.; Chan-Park, M. B.; Li, C. M.; Chen, P.; Carbon 2012, 50, 4865.

63. Yang, Q.; Hou, Z.; Huang, T.; J. Appl. Polym. Sci. 2014, 1, 41615 .

Submitted: January 13, 2020

Published online: July 6, 2020 